ISSN: $1130-3743$

\title{
APRENDIZAJE EN ADULTOS Y PARTICIPACIÓN SOCIAL: UNA PERSPECTIVA AUSTRIACA
}

\section{ADULT LEARNING AND SOCIAL PARTICIPATION: AN AUSTRIAN PERSPECTIVE}

\author{
WERNER LENZ \\ Institut für Erziebungswissenschaften der Karl-Franzens. Universität Graz, 8010 Graz.
}

RESUMEN

En paralelo con el aumento cuantitativo de la participación de los adultos en educación en la mayor parte de los países occidentales, el artículo destaca la necesidad de promover la vertiente cualitativa de este tipo de participación. Para ello se trata básicamente de promover un tipo de educación dirigida a personas adultas basada en el desarrollo de los aspectos afectivos y emocionales, de la interacción personal, del desarrollo de los procesos de auto-aprendizaje, concediendo un papel más activo al individuo; en suma, un tipo de educación que suponga, además de otros elementos, la construcción de conocimiento y la producción de cultura. El fondo del artículo destaca la idea de que la participación educativa de los adultos debe servir para promover un efectivo desarrollo democrático que trascienda el marco particular de cada país, contribuyendo, en nuestro contexto, al impulso de la Europa Unida.

\section{SUMMARY}

Together whit the increase cuantitative of adult participation in the occidental countries, this article proposes the necessity to promote a type of eduction for adults persons that develop emotional and affective aspects, to develop self-learning processes and facilitate personal interactions in social context. Specificaly the acquisi- 
tion of information and the construction of knowledge and, also, producing of culture. This kind of adult education must contribute to effective effort to expand democratic particpation into European Union.

MIND THE GAP!

The field of adult education/continuing education has gained even more popularity during recent years. The constantly rising numbers of participants give evidence of this tendency towards adult learning. Nevertheless there are still many fields of interests - according to empirical studes- which have been articulated but not yet covered by adult education. Although satistics sometimes reflect a limited perception of reality it has been proved that the course provisions in the field of adult education have been enlarged significantly. Wilhelm Filla (1995, p. 58), the secretary general of the Austrian Folk High Schools comments on the situation: "From a quantitative point of view there is no need whatsoever to talk about a crisis, looking at the field in terms of quality is another story". The often insufficient variety of courses provided, the lack of quality in teaching and the unequal participation of certain groups of society are the main reasons for such a critical résumé.

To give you a different perspective on the topic I would like to mention the situation of adult education in another part of the world. "Academic Continuing Education" - continuing education at universities - has become very popular in the United States. As opposed to the German speaking countries there has been a strong link between education and society ever since the United States were founded. Continuing education has a very long tradition. The communal effort for adult learning has been institutionalized at universities: many of them have "Departments of Continuing Education". The participation in programmes of adult learning has risen from 3 Million to 6,6 Million people from 1970 to 1993. (For the following see: Johnson, 1995) This clearly reflects a high demand for continuing education in the US. As the professional world is constantly changing, so is the profile of the required professional skills. The workforce is confronted with a constantly changing working environment and is therefore more and more in need fo continuing education. The providers of continuing education are responding to the new situation of their "customers": market reserch, target group analysis, advertising strategies, specifically designed intensive short courses and the use of new teaching and learning technologies have become a crucial part of their agenda. Not only courses in vocational training but also liberal arts courses are gaining in popularity. As the American university system has been established to educate people in a holistic way, vocational training is not separated from general education: the university environment should stimulate students not only to grow professionally but also personally.

When continuing education was institutionalized at universities the basic idea was to offer academic training to an audience which would not be able to participate in university programmes otherwise. Whether this goal can ever be reachez 
or not is difficult to say. A high percentage of the participants in adult education already possess a university degree from a university or at least attended some kind of institution of higher learning. In general it is more likely for people with some kind of higher education or a high level of professional experience to participate in programmes of continuing education than for people without this educational background.

When looking at the results of empirical research from different countries it can be concluded that continuing education does not contribute to diminish social inequality but rather reinforces the development of new social gaps: educated versus non-educated becomes a new category in the classifying systema. At some stations in the London undergroung an anonymous voice will warn the waiting people: "Mind the gap!" Should there not also be wsuch a warning with regard to education? Has it not been proven again and again that the gaps between different members of our society on the one hand and the gaps between the societies as members of a world community on the other are constantly growing? Participation in and access to education and continuing education is not a regulated process functioning according to fairness principles but has to be organized against existing societal tendencies.

To avoid any misunderstanding: we are pleased about each single participant in courses of adult education - in Austria it is about 15\%, in Germany 28\%, in Denmark one third and in the USA even 50\% (for many professions continuing education is mandatory) of the general population taking part in the programmes. But at the same time it should not be forgotten that a high percentage of our population is still not participating in institutionalised forms of continuing education. Therefore: Mind the gap!

\section{WHAT DOES "PARTICIPATION" MEAN?}

When looking at publications on continuing education tye term "participation" usually corresponds to "participation in courses of academic training". Research on participation concentrates on the social differences of the participants, their learning experiences and their education background. Connected to questions of participation a new research area has opened up: Biographies are being told, transcribed and analysed. This approach offers new ways of looking at the situation of the individual, his or her relationship with society and societal structures in general. It also helps to provide exciting material on educational paths, the interruptions and detours and the resulting successes and disappointments.

In the following I would like to draw attention to some other aspects of "participation" and maybe initiate a new form of discussion of the topic.

We are living in a world of constant changes. Due to new developments in science and technology we find ourselves confronted with instability and rapid reorganization of our environment. Living in a modern or post modern age has made it more difficult if not impossible for the individual to make decisions which might have social and personal consequences. At the same time education has 
been used as a means for adaptation to what is considered a stable reality. But how can we exist as part of a world which is constantly changing, disappearing and reappearing?

The world has become more global. An international network of social relations which makes long distance cooperation possible has been established. Decisions being made at "one end of the world" can have an immediate impact on the social and economic situation somewhere else: e.g. more and more companies have their product being produced in a different country with the guarantee of high quality at a lower cost (compare Giddens, 1995, p. 84 ff.). How can we learn and be empowered to realize, evaluate and react so such global decisions?

The political impact of these questions becomes evident at a different level. We actively part in the production of inequality - our high standard of living and incredible wealth is based on the extreme poverty and exploitation of other countries and people. How can we learn to function and live in a democratic society of free enterprise which does not build its wealth on the poverty of others?

\section{EDUCATION OF FEELINGS?}

Adult education believes that people who acquire knowledge and different abilities do participate more actively in society. To assist people during this process is one of the contributions adult education can provide. In my opinion this kind of participation can be divided into two levels which are closely related to each other: the level of qualification and the level of emotions. The question of qualifications has been discussed within the field for some time. They result in the end in the continuous availability of people and the adaptation of human talents to changing economic needs.

Not much attention has been paid to the level of emotions when discussing learning intentions in adult education. I think in future we should devote more time to research into this important area.

Today we are talking a lot about modernization of society. Old authorities are being denied. The individual has to take the inmediate responsibility for his or her personal decisions. Individualization is the key word. The following are some of the side effects of this phenomenon: the turning away from guiding superior forces, mobility, questions of the individual's sense of belonging, necessary mobility in the professional world, unemployment. A politically motivated instability and insecurity caused by the frequent confrontation with foreing cultures define the environment of an individual who is lonely, insecure and isolate. The reactions to these threats can be manyfold: fundamentalist movements which reject any kind of new development without arguments, the "let's have fun generation" shich enjoys the "now" in a consumer oriented society, people who turn their backs on moderns society and leave it for some alternative way of life.

I sometimes ask myself whether the participation in educational courses and programmes could not be interpreted as the attempt to escape isolation and loneliness. In this sense participation in education would offer a way of participating socially. 
In my opinion participation in education also appears to be connected to a certain kind of hope: the hope to find truth. The idea of being saved in a secular world comes to mind. Education becomes a tool for people who believe in reason, people who believe that we can represent and describe the world as it is and as a consequence will be able to establish clear rules of behaviour. Education becomes a tool to protect ourselves from a world which is unsafe and constantly changing. Education becomes a supplement and complement for faith in order to feel solid ground under our feet.

We tend to forget that reason is only one way of perceiving the world and that we as constantly changing human beings are part of the common instability of the world. In my opinion education can only help us to reflect on some situations but not to pin them down and explain them.

Education as a chance to participate in an ever changing world if it continues to reflec on our own position in it. Education that teaches and helps us to accept the transitory nature of human existence. There is still a lot of scope for critical thinking on such a concept of education.

\section{HUMAN IMAGE}

A few ideas about the human image: We still consider the adult -including ourselves - as a solid, completed, finished human being. But human individuals are not static but dynamic. We should think about the human being as a process and not as something imoble, rigid. (compare: Rogers, 1987). Each activity and each experience means development. At the same time we are all governed by time. The only thing we can take for granted is that our participation in life does also mean that we are mortal and that we are constantly progressing towards this end.

I would like to put it in a more positive way: we do not exist but we become. Education should not help to keep us in place but accompany us along the way.

In my interpretation I do not understand education as some kind of instrument which is able to guarantee fundamental security (a secure position in life) but as a strong support along the way of human development. In such a way education can become part of the social and individual network of human relationships.

In what sense does our society change? Which consequences do these changes have for the individual? In the near future the fast moving dathighways will be some of the most influential factors of change a global society of information is being established. It will become impossible for the individual to use the datahighways and the internet without leaving traces. His or her working hours, health conditions, traveling plans, shopping habits, preferences for entertainment and interests in continuing education will be traceable and therefore also visible for everyone.

It has been very much criticized in Austria that the government suggested to install a system of supervision which should help to prevent crime. Such a system 
would be a major step towards a highly controlled society - byg brother is sending his best regards. The increase of governmental power is closely linked to a decrease of the freedom of the individual.

Uncertainties are growing, fears are being nourished - and wars and violence have become part of our immediate reality. We are looking for protection by governmental forces because we have lost trust in interpersonal and emotional relationships. As Nobert Elias put it: We have forgotten how it feels to be dependent on each other. This seems to be a good explanation for all the changes going on at the moment. Jealousy and envy, the feeling of being threatened or being discriminated against are sources for the little wars we fight against each other every day. The destabilization of a feeling of belonging creates a group of disadvantaged people who are in danger of becoming victims of authoritarian forces.

Which kind of educational programmes can a democratic society offer to strenthen the selfesteem of its members, to reduce their fears and to help them to live their lives in a constructive way?

"We are educated by nature, by people or by things" says Jean Jacques Rousseau in his "Emile". To put it in a more modern context: We are the result of social conditions. In what way can education shape and rebuild these relationships that they become the basis for a happy and peaceful togtherness?

\section{INFORMATION, KNOWLEDGE, EDUCATION}

Although we know that we are transitory we are looking for security and stability. Although we are aware of the constant changes, we try to preserve it. As changes are part of our lives so is the fight for stability.

We do not hesitate to define knowledge as a fixed entity which we want to preserve and protect by means of education. In our age of information knowledge disappears. Information is floating through us, is dominating our lives. It has become difficult to decide which kind of information is worth knowing. The process of learning consists of two dimensions nowadays: the acquisition of information and the construction of knowledge or information which is worth knowing.

Nowadays the acquisition of information could be compared sith the attempt to keep one's head above water in the river of communication. Or to put it in other words: to keep up with the regular speed on the datahighway. To be informed means to be able to receive information quickly and easily, to skim it, to use it and to store it -on floppy disks- in order to have enough space for new incoming information. To be informed appears like a bargain, a shopping trip to the supermarket where goods are available. They can be used, thrown away and usually there is a substitute available.

To produce knowledge on the other hand requires more time and moves at a slower pace. Erwin Chargaff (1995) who undertakes research in the Natural Sciences presented an interesting image when trying to divide knowledge from information: knowledge is something we look for with our souls, information is being delivered to our front door without having ordered it. 
Knowledge or what is worth knowing is defined by social conventions or personal decisions. A fixed entity of collective or individual knowledge helps us to gain security in our daily actions. In such a way knowledge is static, we relate to it shen thinking and acting. Knowledge functions as a kind of personal guide, it gives orientation. If ever questioned, criticized or doubted knowledge in this sense becomes inconvenient and problematic. Since one of the main responsibilities of academic research is questioning certainties, academia is often disliked. It is therefore not surprising that universities as the instituitionalized form of this questioning is criticized. An approach which believes that knowledge can be produced without resistance, ambivalence or doubting is much favoured.

In my opinion the meaning of education can not be the collection and reproduction of information. Education functions in a network of different processes: some that helpe to constituye knowledge and some that enhance critical analysis with room form doubts and value judgements.

Education includes social and individual participation: the social component includes the production of knowledge and information. The individual component comprises the selection, emphasis, combination and the relations that are set up. The two aspects cannot be discussed separate from each other, they belong together like the two sides of a coin.

Education in the sense of participarion means participating in and producing of culture. Social interaction whether in personal or social relationships. Whether in small companies or huge organizations depends on the participant's level of education. In that sense social interaction is not linked to which school, universtiy or other education institution one went, but it is related to the willingness of the people who interact and actively help to shape our society. Education as interfering thinking and acting represents for me the crucial meaning of participation.

\section{Education and Democratic Participation}

In the United States the policy of education has been highly influenced by publications of conservative thinkers lately. (e.g. Bloom: The Closing of the American Mind, 1987) They suggest the production of an elite as the main purpose of higher educaton: "excellence" instead of "mediocracy" is the key word. Educational programmes for the excellent should replace especially designed programmes for the disadvantaged. Such an educational policy only enlarges the gap between the educated and non-educated. What these publications suggest implicitly is to provide optimal learning conditions for a select group. Behind this approach lies the assumption that the ones who are the best learners will also be the highest qualified for leading management positions. In adult education this trend would only enforce the inequality which is already inherent in the structure of participation.

Benjamin R. Barber, Professor of Political Science at Rutgers Universtiy, comments on this conservative movement in American society and education in his book "An Aristocracy of Everyone". Referring to the suggestion to select only the highly talented and guarantee them a future is education he writes: "Like the 
gooed theater director who knows that his most important task is to hire fine actors who require little direction to shine, the conservative knows that the gooed educator is the one who seeks out fine students sho require little effort to shine. But the object of public schools is not top credential the educated but to educate the uncredentialed; that is, to change and transform pupils, not merely to explit their strenths. The challenge in a democracy is to transform every child into an apt pupil, and give every pupil the chance to become an autonomous, thinking person and a deliberative, self governing citizen: that is to say, to achieve excellence". (Barber 1992, 12). Barber suggests that democracy and excellence does not have to be a contradiction: "Everyone can become a free and self-governing adult. Everyone can have a stab at happiness'. (Barber, 13) Education's main purpose should not be to educate the equal but it should serve as an important tool in creating equality -in such a way that it helps to compensate existing deficits. It appears to be very important to analuyse the role and function of education thoroughly in order to guarantee continuity for and development of our democratic system. In this context I would like to quote Benjamin R. Barber again: "The fundamental assumption of democratic lif is not that we are all automatically capable of living both freely and responsibly, but htat we are all potentially susceptible to education for freedom and responsibility. Democracy is less the enabler of education than education is the enabler of democracy. Americans need to reexamine the relationship between their schools and their political institutions, between the classroom and civil society, between education and democracy. There was a time when the relationship was taken for granted. Public, private, and religious schools in America's earlier days expressed a common commitment to education as a concomitant of democracy. Historically, the meaning of public education was precisley education into what it meant to belong to a public: education in the res publica -in commonality, in community, in the common constituion that made pluratily and difference possible". (Barber, 13f)

\section{EDUCATION FOR DEMOCRACY}

Adult education which defines itself as an emancipatory force has at the same time always emphasized as its main claim the democratization of knowledge. Knowledge should be available for everyone and have a political function: it should be used to controll power relations and to improve the living conditions for all people. Nowadays it has become impossible to use all the human knowledge available. The scientific findings in the Natural Sciences have become more complex because there are always new discoveries being made. The same is true for the Social Sciences. The constant changes of our social environment require a permanent redefinition of the research conditions. It has environment require a permanent redefinition of the research conditions. It has become necessary to set clear priorities in the different fiels of studies. A problemoriented pragmatic approach to certain topics is preferred to traditional research methods which focus on specialized and highly structured information. 
The claim to democraticize knowledge has didactic consequences. In that context teaching does no longer mean to fill information into an empty container -to use a drastic image-, but rather to work with people who are thoughtful, contemplative and willing to discuss certain topics thoroughly. To adopt such an approach to education has become difficult in our times. The zeitgeist stresses success in achieving cerain goals. There is no time for detours, to come to quick and easy solutions is in fashion. Learning is used as a tool to achieve goals as quickly and effectively as possible. People who take time to think and resist the "speedy" trend are considered to be a threat for the dominating concept of competition. Teachers in adult education and other institutions of learning should ask themselves how they influence or even promote the process of acceleration in learning through their work. To come back to the distinction between knowledge and information which was introduced earlier on, teachers should think whether they are distributors of information or advisers for learners in how they can build up knowledge.

To work in the field of education often goes along with the vision to have some kind of a missionary function in society. I have a strong belief against this assumption: Nobody can be educated but only educate him- or herself.

An environment where grades and certificates are used as means to impart knowledge will encourage the participants to be passive learners. They will not take part actively and creatively in the learning process. If we want encourage learners to take responsibility for the learning process and therefore for their own future we have to promote self-directed learning and self organization. In order to use such an approach we need space, material, libraries, guidance and opportunities for communication.

Above all it appears to be of crucial importance that we acknowledge our learners as contantly changing individuals. Educational programmes can be seen as contributors to the development of adults! As an individual the adult constantly interacts with his or her social environment. These interactions are one form of participation in our reality but they also help'to constitute this reality. Reading Bourdieu one fins the statement: "In the social world relationships are the only thing existing." (Bourdieu 1989, 71.) If education and adult education in particular wants to respect the individual as a unique and permanently developing human being, it has to accept the inequality and differences beween people. Not the attempt to "make equal" should be our foremost educational goal but how to deal appropriately with inequality. I do not have a simple answe but I think that we have to establish an approach to teaching — not only in teaching adults- which includes: curiosity, interest, openness, patience, calmness...

\section{LEAVING BEHIND AND STARTING ANEW}

The process of European integration currently taking place will cause new political and social constellations. To put these changes into a more global context we are confronted witha world society threatened by wars, hunger, environmen- 
tal destruction and international division of labour. Under these circumstances we have to ask ourselves whether it will be possible to maintain our social and cultural achievements. The effort to expand the European Union has created a paradoxical situation: the individual states - some members some not- are putting more emphasis on the preservation and construction of national particularities. Above all the main common goal seems to be to save civilization. Which role can we as learners play in this development? What we have to suggest appears as a very humble attempt when looking at the current situation of our society: the economical forces have created a situation where a democratic system does no longer stand for wealth but also for suffering and inequality: Nevertheless I still miss joint efforts for the establishment of a European basic curriculum with a thematic focus on "Living in a democracy" and courses on the development of Europe.

Such a programme would have as its main goal to build up knowledge, to initiate models of behaviour and changes in our consciousness. Apart from this I believe it to be especially important that we learne to live and cope with situations of insecurity and change in our modern society. People need to be motivated to look at the world with a different perspective where the replacement of old patterns does not only mean loss but represents a chance for creation of something new. The history of this century already tells many stories about how we have dealt with changes in a very brutal and violent way. We could still use innovative contributions to the project "civilization". What is crucial to this project is the willingness to be open for new developments and a tolerance for people as human beings sho can still teach us something about the world.

I do not look at the future development of the world as some kind of retort or experimental field for adult education. But I am convinced that education and continuing education will be of crucial importance in our society. It is not always easy and does of course not happen by itself, but we should learn to develop some pride for our work and discuss and celebrate the successes more publicly. The negatiuve consequences become obvious enough where our efforts are being hindered or decrease and violence becomes the main force of an argument. We have to fight against such tendencies as long as we have still time, courage and energy left.

At the same time we have to realize that there are no real alternatives: we have to deal with the "now" and" tomorrow" beacause there is no way back. I would like to conclude with one of Friedrich Nietzsche"s thoughts which he published in his "Speech of consolation for a desperate progress" (Nietzsche 1988, 206): "Our time appears to be an age of temporary condition; the old ways of looking at the world, the old cultures are sitll around us in fragments, the new ideas are not yet established and we have not become used to them yet, there is no completeness and consequence in them. It looks like as if everything would turn into chaos, as if everything old would be lost and as if everything new would be no good and become weaker and weaker...

We hesitate but at the same time it is necessary that we overcome our fears and believe in the new achievements. Above all there is no way back into the old, we have burnt the ships. All we can do is to be brave, whether something will come of our efforts or not". 


\section{REFERENCES}

BARBER, B. R.: And Aristocracy of Everyone. The Politics of Education and the Future of America. Oxford, New York 1992.

Bordieu, P.: Satz und Gegensatz. Über die Verantwortung des Intellektuellen. Berlín 1989, S. 71.

Chargaff, E.: Über das Recht, nicht zu wissen. In: Die Presse, Spectrum vom 22. Juli 1995, S.I.

FiLlA, W.: Zukunft der Volkshochschule. In: Filla, W., Heilinger, A., Knaller, H. (Hrsg.): Zur modernen Volkshochschule. Jahrbuch Volkshochschule 1994/95, S. 57-76.

GIDDENS, A.: Konsequenzen der Moderne. Frankfurt am Main 1995.

Johnson, S.: Continuing Education: College à la Carte. In: The New Yorg Times August 16, 1995, S. $22 \mathrm{ff}$.

NiETzSChe, F.: Menschliches, Allzumenschliches. Sämtliche Werke. Band 2. München 1988.

Rogers, C.R.: Der neue Mensch. Stuttgart 1987. 